\section{Intensive Care Medicine}

Edited by Andrew Rhodes MRCP FRCA Consultant in Intensive Care

St George's Hospital Medical School, London

\section{The recognition of a sick patient}

Martin A Whitehead MRCP,

Senior House Officer in Intensive Care

Zudin Puthucheary MRCP,

Clinical Fellow in Intensive Care

Andrew Rhodes MRCP FRCA,

Consultant in Intensive Care

Department of Intensive Care, St George's Hospital, London

\section{Clin Med JRCPL 2002:2:95-8}

It is essential to notice a patient's deteriorating condition if timely intervention is to have a chance of saving that patient's life. Doctors are often poor at recognising these seriously sick patients and this has led to reports of suboptimal care and delayed referral to either a high dependency unit or intensive care unit $(\mathrm{ICU})^{1,2}$

\section{Suboptimal care before intensive care}

A recent confidential survey of two centres in the UK reported that up to $41 \%$ of admissions to the ICU were potentially avoidable and up to $50 \%$ of the patients had received 'suboptimal' standards of care prior to transfer to the ICU ${ }^{1}$. This suggestion is backed up by data around the world ${ }^{2-5}$. In the USA, the majority of in-hospital cardiac arrests can be predicted and, if recognised, the event might be prevented $^{3}$. In most instances, patients at risk of developing critical illness have signs of organ dysfunction, usually caused by inadequate tissue oxygenation. The most commonly disturbed variables prior to cardiac arrest are signs of respiratory distress and alterations in mental state. Deterioration in respiratory function is the best warning sign prior to ICU admission from the general wards. During the six-hour period before admission to the ICU, 75\% of the patients had required oxygen, $37 \%$ had arterial blood gas analysis, and in $61 \%$ of patients oxygen saturation was measured and found to be less than $90 \%$ in $63 \%$ of these. The commonest physiological abnormality identified in this study of sick patients was a respiratory rate of over 25 breaths $/ \mathrm{min}^{4}$.

\section{Key Points}

Deterioration in respiratory function is a sensitive predictor of increasing severity of illness

Screening tools using basic observations can be used to identify individuals at increased risk of critical illness

Arterial blood gas analysis provides valuable information about a patient's respiratory, cardiovascular and metabolic state

Lactate levels and base excess are independently correlated with mortality in all pathologies

KEY WORDS: CPD, acid-base, base excess, blood pressure, emergency, heart rate, lactate, outcome, recognition, respiratory, severity
Abnormalities in the temperature, heart rate, blood pressure, respiratory rate, urine output and consciousness level can all be used to predict critical illness ${ }^{5}$. Although these markers have a low specificity, the sensitivity is high and they can be used to triage patients. Over two-thirds of in-hospital cardiac arrests have severe derangements of these commonly measured variables in the six hours preceding the event. Initiating early appropriate treatment might reduce the incidence of this complication $^{2}$. However, problems can still exist even when these warning signs are recognised. In a study to develop strategies to prevent in-hospital cardiac arrest, Franklin ${ }^{3}$ reported that even when deterioration was correctly documented, there were failures:

- of notification of appropriate personnel

- of the physician either to request or correctly interpret arterial blood gas analysis in the setting of respiratory distress

- to resuscitate before transfer to ICU.

\section{The medical emergency team}

Abnormal physiology does not always identify every patient at risk of critical illness. Experienced clinicians and nursing staff can predict complications as well as, if not better than, many sophisticated scoring systems ${ }^{6}$, but the teaching of this intuitive technique is difficult. Nurses rely on four criteria to identify 'at risk' patients:

- the patient complains of feeling 'not right'

- the patient's colour has changed

- the patient is agitated

- there is marginal deterioration in nursing observations ${ }^{7}$.

The realisation that inexperienced staff may not always appreciate the subtle signs of a patient's deterioration has led to a new concept in care: the medical emergency teams and 'outreach' intensive care. These teams are usually multidisciplinary, consisting of experienced physicians, nurses and physiotherapy staff. Their role is to assist and educate 
Table 1. The early warning score ${ }^{8}$.

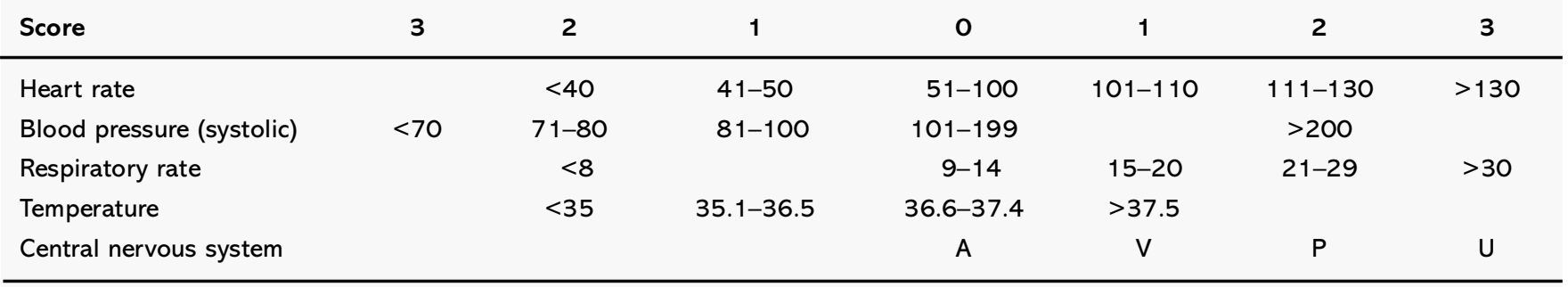

$\mathrm{A}=$ alert, $\mathrm{V}=$ responds to vocal command, $\mathrm{P}=$ responds to pain, $\mathrm{U}=$ unresponsive.

Patients are scored with the above algorithm; the higher the score, the more physiologically disturbed is the patient.

ward-based staff to recognise when patients are developing critical illness, and then to facilitate appropriate referral to a higher level of care. These teams have developed a number of simple and easy-to-use referral criteria that can be activated by any member of the healthcare team. These criteria can be either simple ward-based scoring systems $s^{5,8,9}$ or may also include laboratory results (Table 1$)^{10}$. Other criteria for referral to the team can be specific diagnostic criteria (eg acute pancreatitis) or simply any patient who is causing concern to the ward staff.

\section{Arterial blood gas analysis and lactate}

Any sick patient should have arterial blood gases measured as a routine. This simple test provides information about both gas exchange and the metabolic state of the patient. Although widely used in patients with respiratory failure, this test is often underused in other groups of sick patients. It indicates the patients' cardiorespiratory reserve and ability to cope with their illness.

Table 2. Causes of metabolic acidosis.

$\begin{array}{ll}\begin{array}{ll}\text { Increased } \\ \text { anion gap }\end{array} & \begin{array}{l}\text { Diabetic ketoacidosis } \\ \text { Starvation } \\ \end{array} \\ & \text { Alcohol } \\ & \text { Lactic acidosis } \\ & \text { Salicylates } \\ & \text { Renal failure } \\ \text { Normal } & \text { Diarrhoea } \\ \text { anion gap } & \text { Renal tubular acidosis } \\ & \text { Tubular damage } \\ & \text { Hyperparathyroidism } \\ & \text { Acetazolamide } \\ & \text { Excess chloride infusion }\end{array}$

To assess alveolar gas exchange, and hence the extent of any pulmonary pathology, the $\mathrm{PaCO}_{2}$ should be noted together with the ratio of the alveolar to arterial partial pressure gradient of oxygen $\left(\mathrm{PaO}_{2}\right)$. The predicted $\mathrm{PaO}_{2}$ should be approximately $10 \mathrm{kPa}$ below the percentage inspired oxygen concentration; a figure in excess of this indicates respiratory impairment.

Correct interpretation of the metabolic derangement of the arterial blood gases can provide invaluable information about both the diagnosis and the severity of the patient's underlying condition (Table 2). Such a derangement is quantified by evaluation of either the bicarbonate concentration or the base excess (which corrects for abnormalities in $\mathrm{PaCO}_{2}$ ). Fifty-seven per cent of patients requiring intensive care present with a metabolic acidosis, in $75 \%$ of whom the acidosis is due to a raised lactate concentration $^{11}$. The recognition of a raised lactate level is important because of its association with anaerobic metabolism secondary to cellular hypoxia (Table 3 ). A raised lactate is associated with a higher death rate ${ }^{11-13}$, with a $74 \%$ mor- tality in one series in patients whose lactate level was above $1.5 \mathrm{mmol} / \mathrm{l}$ on admission to the ICU ${ }^{11}$.

Metabolic acidosis is associated with appreciable morbidity and mortality. A base excess of less than $-4 \mathrm{mmol} / \mathrm{l}$ on admission to the ICU is associated with an in-hospital mortality of $57 \%$, which increases to $70 \%$ if it has not corrected to less than $-2 \mathrm{mmol} / \mathrm{l}$ within the next 24 hours $^{11}$, mortality being directly proportional to the degree of the abnormality (Fig 1). The base excess has been shown to be superior to $\mathrm{pH}$ in the evaluation of metabolic acidosis and in the prediction of subsequent complications, but its importance appears to be less clearly appreciated by many junior doctors. The base excess has also been shown to correlate with intravascular fluid requirements and mortality in patients with pelvic fractures, hepatic injuries, hypovolaemic shock and trauma ${ }^{12-16}$.

\section{Conclusions}

Basic scoring systems that use simple physiological and routinely measured parameters are sensitive tools for identi-

Table 3. Causes of lactic acidosis.

\section{Type A: tissue hypoxia}

Type B: decreased hepatic lactate metabolism
Exercise

Shock: traumatic, haemorrhagic, cardiogenic, septic Severe hypoxia

Post-epileptic seizure

Severe liver dysfunction

Haematological malignancies

Metabolic myopathies

Paracetamol excess

Biguanide therapy

Alcohol

Post recovery from diabetic ketoacidosis

Thiamine deficiency 


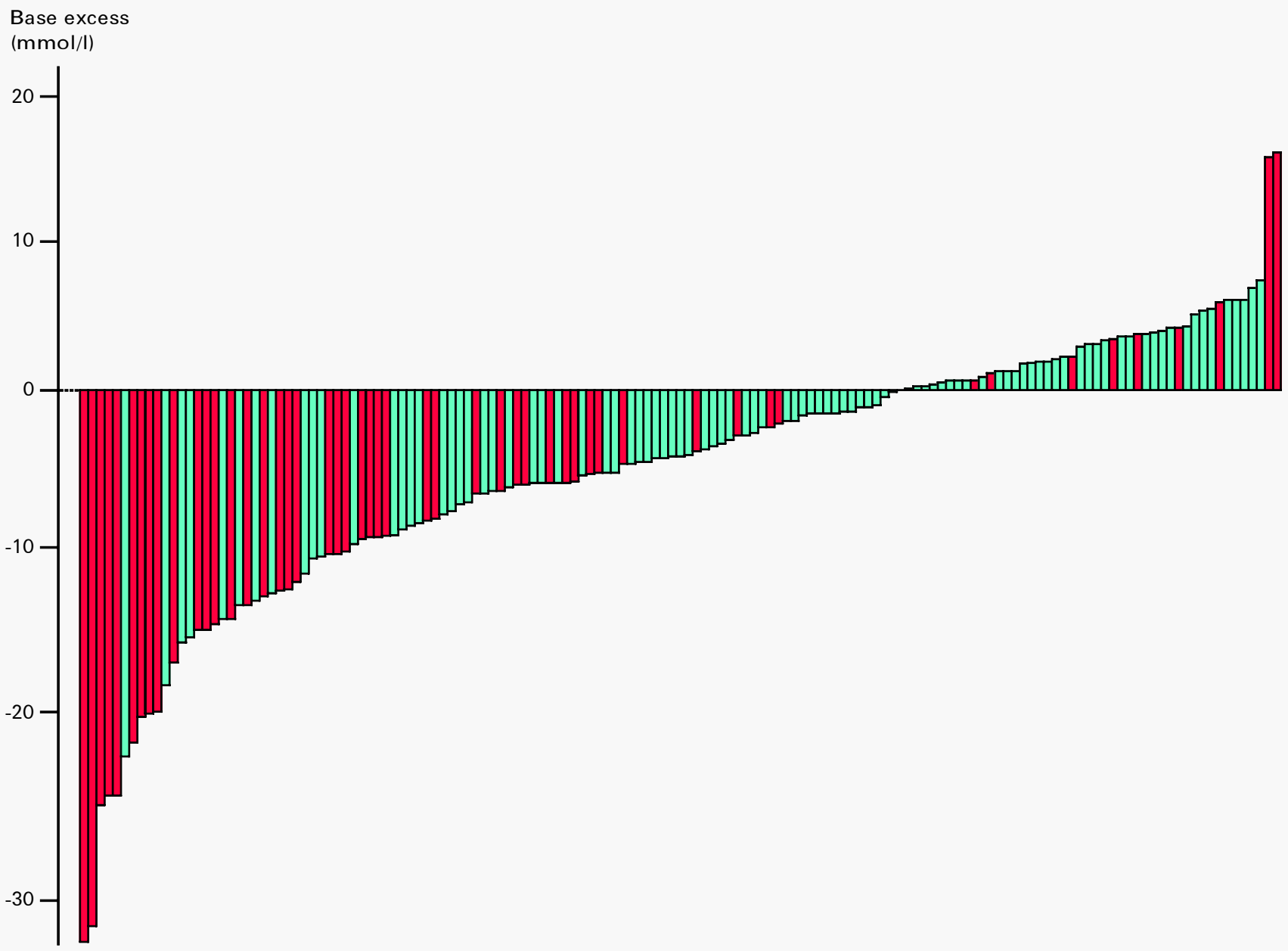

Fig 1. The relationship between base excess and mortality. Each bar represents one patient $($ red $=$ non-survivor; green $=$ survivor $)$.

fying patients whose condition may quickly deteriorate. Where appropriate, further investigations are carried out to enhance the poor specificity of such basic systems, and thus identify those patients in whom intensive monitoring and therapy are required to prevent or minimise the extent of any deterioration. In the vast majority of cases this will include the interpretation of arterial blood gas results.

\section{References}

1 McQuillan P, Pilkington S, Allan A, Taylor $\mathrm{B}$, et al. Confidential inquiry into quality of care before admission to intensive care. $B M J$ 1998;316:1853-8.

2 McGloin H, Adam SK, Singer M. Unexpected deaths and referrals to intensive care of patients on general wards. Are some cases potentially avoidable? $J R$ Coll Physicians Lond 1999;33:255-9.

3 Franklin C, Mathew J. Developing strategies to prevent inhospital cardiac arrest: analyzing responses of physicians and nurses in the hours before the event. Crit Care Med 1994;22:244-7.

4 Goldhill DR, White SA, Sumner A. Physiological values and procedures in the $24 \mathrm{~h}$ before ICU admission from the ward. Anaesthesia 1999;54:529-34.

5 Goldhill DR, Worthington L, Mulcahy A, Tarling M, Sumner A. The patient-at-risk team: identifying and managing seriously ill ward patients. Anaesthesia 1999;54:853-60.

6 Kruse JA, Thill-Baharozian MC, Carlson RW. Comparison of clinical assessment with APACHE II for predicting mortality risk in patients admitted to a medical intensive care unit. JAMA 1988;260:1739-42.

7 Cioffi J. Recognition of patients who require emergency assistance: a descriptive study. Heart Lung 2000;29:262-8.
8 Morgan RJM, Williams F, Wright MM. An early warning system for detecting developing critical illness. Clin Intensive Care 1997;8:100.

9 Stenhouse C, Coates S, Tivey M, Allsop P, Parker T. Prospective evaluation of a modified early warning score to aid earlier detection of patients developing critical illness on a surgical ward. Br J Anaesth 2000;84: 663P.

10 Hickey C, Allen MJ. A critical care liaison service. Br J Anaesth 1998;81:650P.

11 Smith I, Kumar P, Molloy S, Rhodes A, et al. Base excess and lactate as prognostic indicators for patients admitted to intensive care. Intensive Care Med 2001;27:74-83.

12 Davis JW, Kaups KL, Parks SN. Base deficit is superior to $\mathrm{pH}$ in evaluating clearance of acidosis after traumatic shock. $J$ Trauma 1998;44:114-8.

13 Siegel JH, Rivkind AI, Dalal S, Goodarzi S. Early physiologic predictors of injury severity and death in blunt multiple trauma. Arch Surg 1990;125:498-508. 
14 Dunham CM, Siegel JH, Weireter L, Fabian $\mathrm{M}$, et al. Oxygen debt and metabolic acidemia as quantitative predictors of mortality and the severity of the ischemic insult in hemorrhagic shock. Crit Care Med 1991;19:231-43.

15 Davis JW, Shackford SR, Holbrook TL. Base deficit as a sensitive indicator of compensated shock and tissue oxygen utilization. Surg Gynecol Obstet 1991;173:473-6.

16 Davis JW, Kaups KL. Base deficit in the elderly: a marker of severe injury and death. J Trauma 1998;45:873-7.

\section{Early management of the critically ill patient}

Zudin Puthucheary MRCP,

Clinical Fellow in Intensive Care

Martin A Whitehead MRCP,

Senior House Officer in Intensive care

Michael Grounds MD FRCA,

Reader in Intensive Care

Department of Intensive Care, St George's Hospital, London

\section{Clin Med JRCPL 2002:2:98-100}

Without an adequate supply of oxygen, cell mechanisms fail and the patient dies. The priority in the early management of a sick patient is therefore to ensure adequate levels of cellular oxygenation. Although many disorders can account for an acute deterioration in a patient's status, the early management principles are similar and revolve around the basics of supporting the patient's airway, breathing and circulation.

\section{Airway management}

The first priority in managing an acutely sick patient is to ensure patency of the patient's airway and to give the patient oxygen (Table 1$)^{1}$. The aims of airway management are to maintain adequate oxygenation and to prevent aspiration of gastric contents into the tracheo- bronchial tree. These aims can best be achieved by giving oxygen with an appropriate device (Table 2) while maintaining patency of the airway. This may be relatively simple, merely requiring support of the jaw, or more complex, necessitating tracheal intubation.

The airway can be intact, partially obstructed or completely occluded. Even if the airway is open, loss of the normal protective reflexes can leave the patient susceptible to aspiration of gastric secretions. Although loss of the gag or cough reflexes is usually obvious, they should be considered inadequate if the Glasgow Coma Scale score is less than eight. Complete obstruction of the airway is usually self-evident, but partial obstruction is not always so easy to diagnose. Partial obstruction presents as inspiratory stridor, or 'snoring' if the obstruction is due to a loss of pharyngeal tone, or as expiratory wheeze if the obstruction is below the larynx. In the presence of spontaneous breathing, partial obstruction can present as paradoxical movements of the chest and abdomen.

When the patency of the airway is compromised, it should be treated with utmost urgency. The basis for the steps taken is that the genioglossus muscle attaches the tongue to the mandible and thus techniques that displace the

\section{Key Points}

Early appropriate treatment of acutely ill patients is vital in order to maintain adequate cellular oxygenation and to prevent a decline into organ failure and death

When the patency of the airway is compromised, it should be treated with utmost urgency. This includes simple manoeuvres of the jaw up to and including endotracheal intubation

Appropriate amounts of oxygen must be delivered to tissues. This can be achieved with a variety of delivery devices. Effectiveness can be assessed by arterial blood gas measurement or peripheral oxygen saturation

Circulatory resuscitation is imperative in shocked patients to allow adequate delivery of oxygen to the vital organs. Oxygen delivery has three main components - oxygen saturation, haemoglobin concentration and cardiac output - all three of which must be adequate for optimal resuscitation

KEY WORDS: CPD, airway, breathing, cardiac output, circulation, delivery, mask, oxygen, saturation, ventilation 